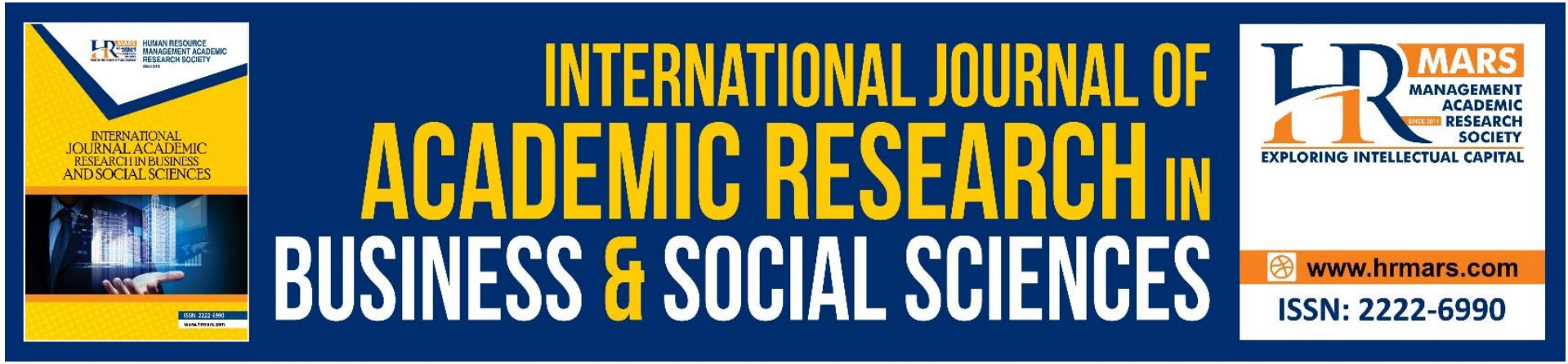

\title{
How Teachers' Meaning Making Processes During Teacher Literature Circles Transcend Into The Classrooms: Teacher- Sharing Of Personal Experiences In A Malaysian School Context
}

Angeline Ranjethamoney Vijayarajoo, Moses Stephens Gunams Samuel, Lydia Colaco

To Link this Article: http://dx.doi.org/10.6007/IJARBSS/v11-i9/10980

DOI:10.6007/IJARBSS/v11-i9/10980

Received: 18 July 2021, Revised: 10 August 2021, Accepted: 29 August 2021

Published Online: 09 September 2021

In-Text Citation: (Vijayarajoo et al., 2021)

To Cite this Article: Vijayarajoo, A. R., Samuel, M. S. G., \& Colaco, L. (2021). How Teachers' Meaning Making Processes During Teacher Literature Circles Transcend Into The Classrooms: Teacher-Sharing Of Personal Experiences In A Malaysian School Context. International Journal of Academic Research in Business and Social Sciences, 11(9), 122-130.

Copyright: (C) 2021 The Author(s)

Published by Human Resource Management Academic Research Society (www.hrmars.com)

This article is published under the Creative Commons Attribution (CC BY 4.0) license. Anyone may reproduce, distribute, translate and create derivative works of this article (for both commercial and non-commercial purposes), subject to full attribution to the original publication and authors. The full terms of this license may be seen

at: http://creativecommons.org/licences/by/4.0/legalcode

Vol. 11, No. 9, 2021, Pg. 122 - 130

http://hrmars.com/index.php/pages/detail/IJARBSS

JOURNAL HOMEPAGE

Full Terms \& Conditions of access and use can be found at http://hrmars.com/index.php/pages/detail/publication-ethics 


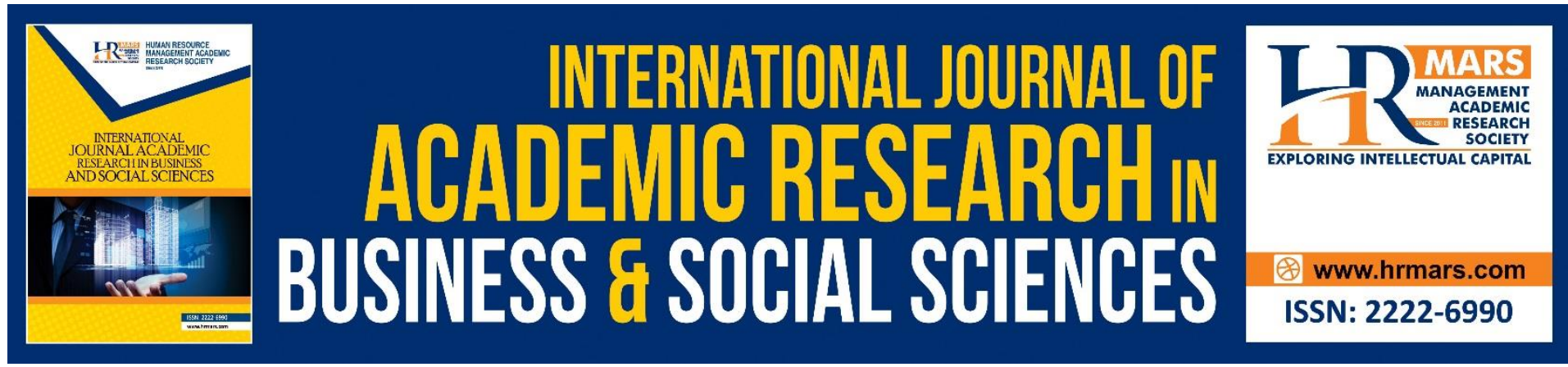

\title{
How Teachers' Meaning Making Processes During Teacher Literature Circles Transcend Into The Classrooms: Teacher-Sharing Of Personal Experiences In A Malaysian School Context
}

\author{
Angeline Ranjethamoney Vijayarajoo ${ }^{1}$, Moses Stephens \\ Gunams Samuel², Lydia Colaco ${ }^{3}$ \\ ${ }^{1}$ Academy of Language Studies, Universiti Teknologi Mara, Negeri \\ Sembilan, Malaysia, ${ }^{2}$ Faculty of Social Sciences \& Leisure anagement, \\ ${ }^{3}$ SMK Ghafar Baba, 78300 Masjid Tanah, Melaka, Malaysia
}

Email: angierv@uitm.edu.my,moses.samuel@taylors.edu.my, lydia.colaco@gmail.com

\begin{abstract}
When the new novel was introduced by the Ministry of Education in 2015, the teachers were concerned with how they were going to make meaning of the new text for themselves and then to help their students to make meaning of it in classrooms. At this point in time, the researcher asked for volunteers to form a Teacher Literature Circle (TLC). A Teacher Literature Circle is an informal gathering of teachers to discuss a literary work on a regular basis, in order to facilitate understanding of the text. Four teachers from an urban school participated in the study. The Teacher Literature Circle (TLC) discussions took place weekly for seven consecutive weeks, each session varying from two to four hours each. Data comprised the transcripts of every TLC discussion and the interview data of the teachers after the TLC discussions. The findings revealed that one of the ways in which the teachers made meaning of the text was by sharing personal experiences in the TLC. It was also found that the teachers brought their meaning making processes into the classrooms, to enable the students to understand the text better as it informed and influenced their classroom practices. Hence, TLCs were a means for teachers to learn together, transfer their meaning making processes to, and improve their teaching practices in the classroom settings.
\end{abstract}

Keywords: Teacher Literature Circles, Sharing Personal Experiences

\section{Introduction}

Busy school days seldom give opportunities or time for teachers to talk socially or professionally. Present day school systems have set higher and higher standards and goals for student learning. However, the reform visions depend greatly on teachers to make the changes in classroom practices. It seems that despite the billions of dollars spent on professional development programmes, these have been found to be fragmented, 
intellectually superficial and do not take into account what is known about how teachers learn (Bell \& Cohen, 1999; Putnam \& Borko,1997, cited in Borko, 2004).

In 2010, a new cycle of literature texts were introduced into the Malaysian English Language Syllabus (Secondary Schools) by the Ministry of Education, thus situating the current study at a point of text- change with the need to understand the text and to prepare to teach the new text to students.

Basically, Teacher Learning Circles or TLCs, as defined by Daniels (1994) are 'small temporary groups who have chosen to read and discuss the same work of literature'. TLCs are a mode for educators to get together and enjoy literature and the social nature of a book club as they consider literacy from different angles. When teachers are exposed to this exchange, they will be able to understand the text better as well as construct and co-construct ideas collaboratively, that they can bring back into the classrooms. Teachers can also better understand students' needs as readers by engaging in reading and being readers for themselves, reflecting on their own reading styles and responses to literature.

\section{Literature Review}

It has been found that when teachers discuss literature, not only do they analyze their personal preferences for reading but they also reflect on classroom practices and consider ways of modifying these classroom practices on the basis of what they have gathered from one another's experiences (Raphael, Pardo, Highfield, \& McMahon, 1997).

Wilhelm (2009) states that teachers must inquire into 'the issues we teach, into how we teach and by having the courage to continually make the changes that our reflective and reflexive stances suggest to us' (p. 12). So 'how we teach' can be interpreted to include sharing personal experiences among colleagues. This study suggests that Teacher Literature Circles are a mode that could help teachers to make meaning of a text when sharing their personal experiences.

In the past, teachers viewed reading as a series of skills that had to be mastered in order to get the meaning which came solely from the text. Current views of literacy instruction differ. The philosophy that the reader and the context also contribute to meaning is now a significant part of the reading process where Rosenblatt conceptualizes readers' experiences as 'multiple inner alternatives' (Rosenblatt, 2004, p. 24). Some aspects of these 'multiple inner alternatives' include the sharing of personal experiences. Hence, it is likely that during TLCs, these aspects would arise and help teachers in their learning and later, in their teaching, besides facilitating student learning.

For many years, researchers have written about the isolation of teachers and the harm that it brings to their continued learning and development (Lieberman \& Miller,1994; Lortie, 1975; Sarason, 1982). Little's $(1982,1986)$ seminal work showed that teachers who worked together not only build commitment among themselves but also built further learning. TLCs can be seen as an opportunity for professional development as the teacher network helps the teachers to solve problems that they have identified in their practice (Clarke, 2001). Such an organization also works against the traditional isolation of teachers from other teachers so that they can craft a new professional community for improving practice (Raphael et al., 2001). Learning together also includes 'struggling' together and it helps teachers to learn by way of mastering new practices. This study shows that one of the ways teachers learned was by sharing their personal experiences during TLC discussions. Lieberman (2010) cites NWP (National Writing Project) as a good example of colleagueship after studying two sites in 2000, confirming that teachers working together was a powerful way to learn about their own and 
others' practices. During the NWP, teachers learned to share and learn from others and be open to learning as a lifelong process.

\section{Theoretical Framework}

The theoretical framework guiding this study includes reader response theory and socioconstructivist theory. These theories provided a foundation for our conceptualization of the ways in which the teachers made meaning of the text. The focus of this study is the way in which the teachers shared their personal experiences as this was a way for them to make meaning of the text as well. The theories offered an understanding of the discussions in teacher literature circles as an important context and medium through which the teachers brought their own personal experiences into a social context and how they made meaning of the text through these connections.

According to reader response theory, reading is a reflective and creative process where meaning is self- constructed. Fish (1980) informed that readers do not reside in the same context, and reading contexts of an individual change over time. In this study, the focus of the meanings the individuals made of the new text (Catch Us If You Can by Catherine Macphail) came by way of sharing personal experiences of their own, and that of others. Later, the teachers brought these personal experiences into their own classrooms. The directions that the discussions took, between the different teachers and their students varied, due to the different personal experience-contexts of the students. Hence, both, the teachers and students made meaning in changing contexts. This resulted in the opening of other windows within the individuals, in keeping with reader response theory.

Similar to reader response, socio-constructivist theory (Vygotsky, 1962) conceptualizes meaning as a 'dynamic, fluid complex whole', as words change meaning and transition from one sense to another, depending on the context. In this way, Vygotsky's conceptualization of meanings parallel and build on reader response theory where changing contexts result in changing meanings within the individual and the group. The reader is not a passive recipient of meaning that an author has rendered in the text but rather an active maker of meaning. Readers' contexts are not fixed: their past experiences, beliefs, expectations and assumptions differ. Hence, teachers also change, alter or adapt their original meanings and interpretations as they share their own differing personal experiences, which may likely change or add to their own orientations and that of the other teachers. TLCs provide a medium for teachers to make meaning of the text as they share their personal experiences.

What this study shows is that this sharing of personal experiences within TLCs does not stop there but spills over to the classrooms. In the classrooms, both, teachers and students share their experiences, causing contexts to be 'fluid' and changing, with revisions and counter-revisions in progress. Hence, while the reader is not a passive recipient of meaning that the author has predetermined, teachers as readers, bring their own meanings into the text. Meaning is fluid and constantly changing as new windows are opened within individuals as they share their own and listen to the personal experiences of others.

\section{Methodology}

This study used a case study approach within a qualitative interpretive research design. The researcher chose a qualitative approach. Qualitative research is characterized by the search for meaning and understanding. The researcher was the primary instrument of data collection and analysis. In this study, this was through the discussion and sharing of personal experiences among the teachers, which later spilled over into their classrooms. 
The interaction of the group comprising four experienced teachers (Saty, Di, Anne, Aini), as they discussed the new literature text in teacher literature circles served as the 'case'. The case was bounded by the fact that all the teachers were experienced teachers and united by the specific text, 'Catch Us if You Can' by Catherine Macphail.

The main sources of data comprised the transcripts of the TLC discussions and interviews with the teachers after they had gone into the classrooms and completed teaching the text. The TLC sessions took place once a week for 7 weeks, each session varying in duration from two to four hours per session. Other data included interviews with the teachers after they had taught the text to their students, four months after the last session of the TLC. Researcher field notes were also useful as I, the researcher made phone calls or sent emails to the participants whenever I was unsure of the transcriptions or to confirm their interpretations. These 'multiple-sources of information' provided material for an 'in-depth analysis' (p. 65), a rich, thick description within the context of the case (Creswell, 1998; pp. 61-65; Merriam, 1988).

\section{Findings and Discussions}

In the first extract, Aini was able to make meaning of the text grandfather (Granda) by contrasting her own real life grandfather to Granda.

\section{Extract 1}

Ms. Di : Ok, we going to talk about chapters 1 to 5 of the novel Catch Us if You Can. Ms Aini: I really like it [ the novel].

Ms Anne: Especially the character "Rory" ah, the kid, and Granda [grandfather].

Ms Aini: Oh ya... ya, what a fine relationship you know. I didn't have such a relationship with my grandfather you know...

Aini saw the difference between her own grandfather and the text character 'Granda'. She brought this up a little later, in her elaboration of her grandfather's character traits as 'strict' and 'always scolding', which led to a different type of relationship compared to that of the text-relationship situation, between the grandfather and the grandson.

Aini understood 'Granda' to be what her own grandfather was not, or she understood her grandfather to be what the text character "Granda" was not. There seemed to be a tone of regret that she did not have the text relationship (as that between Rory and Granda) with her own grandfather. By presenting Aini's own grandfather and her relationship with him, as a contrast to the text character, 'Granda', and Rory's relationship with 'Granda', Aini was able to make meaning of not only the text but also of her grandfather and her own relationship with him. In the interview with Aini, she said "I wished my grandfather was like Granda".

Later on, during another TLC session, Ms Di shared her classroom experience, taking a thread from this discussion with her colleagues, to her classroom. Di talked about how she posed a question to her students, as to whether they had a similar relationship with their grandparents. Di shared,

".... the boys actually talk to their grandparents more than to their parents". Di further quotes what her student said; 
"Teacher... [ I ] can sit and chat with him [ grandfather], not a problem. No problem is a problem teacher, everything 'jalan' ['jalan' denotes an easy going and informal relationship in the Malay language].

What Di did was to link the earlier discussion in extract 1, of the TLC, into the classroom on relationships with grandparents / grandfathers. In extract 1, it was Aini who had shared her personal experiences and memories of her grandfather and her contrasting relationship with him, to that of the text. Yet, it was not Aini who brought this up in the classroom but $\mathrm{Di}$, another participant of the TLC who was also making meaning of the text, and bringing what had transpired in the TLC with her colleagues, to the classroom.

When Di was asked during an interview with the researcher as to why she asked her students that question, her reply:

"I remembered the discussion at the TLC. I figured that it would be a good way to help the students also... er.. er.. to understand the text better. ......especially if..if they could share their..their own experiences with the rest of the class.... I felt that they [the students] would understand the character of Granda [ text grandfather] and the relationship between Rory and Granda better. Emm.... I er.. was also..also thinking that I could understand this part better because during the TLC discussion, I was also thinking of my own grandfather but didn't share anything of him then. Aini talked of her grandfather ... but my grandfather was a great man.. fun ... If the students could talk ..talk of their own personal relationships, they would be able to make sense of the text..... something like how we [ the teachers in the TLC] did".

What was interesting in the interview data is that Di had not shared anything about her grandfather or her relationship with him during the TLC, but her personal and private thoughts of him were triggered as the TLC continued. I use the term 'private' as Rosenblatt referred to the 'private' domain as the part of the reader that was not shared, while the 'public' domain was the part that the reader shared with the others. Hence, meaning making was taking place in both domains - the public and the private. In this instance, Di was making meaning in the private domain as the TLC was going on, and she brought that part of the TLC into her classroom as she found that it helped her and expected that it would help her students too. This part of the interview data showed that parts of the TLC among the teachers were brought into the classroom. This was because Di felt that these parts had helped her (and perhaps the others as well) to make meaning of the text and would also apply to her students. Aini made meaning in the public domain and that too helped her to make meaning of the text. While the teachers made meanings in different ways during the TLC discussions, they also brought these experiences into the classrooms, where their own, and that of their students, had gone through change, in the private or public domain through the changing contexts brought by different people and their different personal experiences.

Another point of interest was the environment. People share personal experiences only when they are comfortable with each other and feel safe. It was possible that Di was not comfortable in sharing her own personal experience with the TLC group, at that point in time. This has implications for classroom discussions where students need to feel safe to share their personal experiences. This would mean, both the teachers and students need to work together, in creating safe and trusting environments, without making judgements.

During the interview, Aini said that she did ask her students too about their grandparents and 'like Di, most of them [students] had fun and enjoyed having grandparents'. 
When asked why she [Aini] asked her students to share their experiences with their grandparents, Aini replied that she felt that 'by talking about their own grandparents.. grandfather..grandfathers, the students would be able to understand the text better and also ..also understand their own relationships er..er.. better'. The researcher probed and asked Aini why she thought that her students would understand the text and their own relationships with their grandfathers / grandparents better, by sharing their personal experiences. Aini replied:

"When I shared about my own grandfather... and how it was with us.. the grandchildren, I could see how different it was in the text.. and could understand the text as well as how it was with us... If that helped me.. to.. to understand both situations, then I should use this.. er to get the students to share, so that they too can understand. I think there are different types of relationships and it is good to share,. How I wished my grandfather was like 'Granda'”.

This was a clear indication that Aini too, though she had a different relationship with her grandfather, in contrast to the text, found that this contrast showed her the different situations and possibilities that existed. As much as she may have wished for her grandfather to be like Granda, with a good and fun relationship, as it was between Granda and Rory, this was not the case and the reality of life was that 'there are different types of relationships' and that students 'should know and understand this'. Though Aini supported personal sharing of grandfather-experiences, her inclination was toward understanding the text situation and the fact that not all relationships were like that-- as between Granda and Rory. Aini brought her personal and contrasting situation to the text, and to the classroom, just as Di had. Though the common intention of both the teachers was to help students to make meaning of the text, both the teachers had differing personal experiences, which influenced their directions taken in the classroom: $\mathrm{Di}$, toward identifying with a similar personal experience as in the text, while Aini, though acknowledging the extremely good relationship in the text, brought to the attention of the students that not all relationships are like that and that they should be thankful for theirs - just as it was in the text.

Saty, who had started teaching the text in class during the TLC reported a different response from her students when asked of their relationships with their grandfathers. She said "very few raised their hands" when she asked them if they spent fun times with their grandparents.

This brought about responses from Aini during a later TLC session, that children are "getting very impatient with grandparents....". Anne quickly responds that "....there are a lot of other factors, you know that make one impatient...". Di then finds this an open window for her to share her own impatience with older people. "...after I've done it, the minute I said it [showed impatience by words or manner], I know I blundered straight away. My inner voice talks to me - Why did you do that?".

Hence, while Aini had a 'strict' and 'scolding' grandfather, Saty shared her students' contexts of their grandfathers, who were not communicative with them, triggering Di's personal confession of her own impatience toward her grandfather though she experienced a good relationship with him. Di accepted and shared her character flaw of showing impatience towards her grandfather but what came through was her acute awareness of this and a strong sense of an inner voice - perhaps part of Rosenblatt's "inner alternatives" which suggested that she could have responded differently. Di shared her personal experience which helped her to make meaning of the context that Saty had suggested - a context quite 
different from the text, where her students had hardly spent fun times with their grandparents.

Aini's context of a 'strict' and 'scolding' grandfather changed to that of Saty's classroom findings that many of the students did not experience fun times with their grandparents. Aini acknowledged that children were impatient with grandparents - -a turnaround situation from the 'strict' and always 'scolding' grandfather. This context was further explored and explained by Anne, who talked of 'other factors', causing impatience, and later revealed, that these factors were the grandchildren being 'tired.... mentally, really drained..... and its so annoying...."

The sharing of experiences opened up other windows of possibilities and learning among the teachers and students.

\section{Conclusion}

There are the threads of sharing personal experiences among the teachers in the TLC which helped them to make meaning of the text through the similar, contrasting and other possible contexts. Interesting is the way these threads are picked up and connected to the classroom and to the text. During the interview with the teachers, the researcher asked the individual teachers if they brought up personal experiences shared during the TLCs in the classrooms. Saty said that she did and that was when she realized that many of her students did not have a close relationship with their grandparents. This opened up possible reasons for this, through open discussions with her students. The discussions she had were interesting and the contexts ranged from the students' busy schedules to grandparents being 'old school'. Saty was able to put this contrasting context alongside the text context. Parallels were drawn and students made meaning through these exchanges and sharing of personal experiences.

A significant point made by the teachers during the interviews, after the TLCs had ended, was the need to work at creating conducive classroom environments. This would be one way for students to trust the teacher and the establishing of trust among all fellow students in the classroom, in order to share some of their personal experiences. The students also need to feel safe when they share personal experiences, just as the teachers themselves, would have to feel during TLC discussions. To be noted are some points that the teachers did not share in the TLC, but shared in the individual interview with the researcher, implying the need for the private domain, more comfortable environments and a span of time for reflection. Meanings also change with time and further reflection. Not all of these are completely captured in this study.

Having discussed this face- to- face way of teaching and learning, present times are online teaching and learning. The researcher suggests that TLCs are possible online and teachers can form forums, google meets or even other platforms for students to express their views and for others to read and comment. Hence, another area for possible research is TLCs online and the search for the right medium, while looking at the effectiveness of online TLC groups for teachers.

This study opens up windows on some ways in which teachers' meaning making processes during TLCs take place through sharing of personal experiences. These meaning making processes transcend into the classroom, facilitating greater meaning making by the teachers and their students. Hence, the TLCs provided a platform for the teachers to make meaning of the text, meanings which they brought into their classrooms. Further study might 
probe into the formation of online TLC groups and the difference in effectiveness between online and face-to-face groups.

\section{References}

Borko, H. (2004). Professional Development and Teacher Learning: Mapping the Terrain. Educational Researcher, 33(8).

http://www.aera.net/uploadedFiles/Journals_and_Publications/Journals/Educationa I_Researcher/Volume_33_No_8/02_ERv33n8_Borko.pdf

Clarke, D. J. (2001). Negotiating meanings: An introduction. In D. J. Clarke (Ed). Perspectives on practice and meaning in mathematics and science classrooms (pp. 113. Dordrecht, The Netherlands: Kluwer Academic Press.

Creswell, J. W. (1998). Qualitative inquiry and research design: Choosing among five traditions. Thousand Oaks, CA: Sage.

Daniels, H. (1994). Literature circles: Voice and choice in the student-centred classroom. Markham, Canada: Pembroke.

Fish, S. (1980). Is there a text in this class? Cambridge, MA: Harvard University Press.

Lieberman, A. (2010). Making practice public: Teacher learning in the 21st Century. Journal of Teacher Education, 61(1-2), 77-88

Lieberman, A., \& Miller, L. (1994). Teachers: Their world and their work. Alexandria, VA: Association for Supervision and Curriculum Development.

Little, J. W. (1982). Norms of collegiality and experimentation: Workplace conditions of school success. American Educational Research Journal, 19(3), 325-340.

Little, J. W. (1986). Seductive images and organizational realities in professional development. In A. Lieberman \& L. Miller (Eds.), Rethinking school Improvement: Research, craft and concept (pp. 26-44). New York, NY: Teachers College Press.

Lortie. (1975). Schoolteacher. Chicago, IL: University of Chicago Press.

Merriam, S. (1988). Qualitative research and case study applications in education. San Francisco: Jossey-Bass.

Raphael, T. E., Kehus, M., \& Damphousse, K. ( 2001). Book Club for middle school. Lawrence, MA: Small Planet Communications.

Raphael, T. E., Pardo, L. S., Highfield, K., \& McMahon, S. I. (1997). Book Club: A literaturebased curriculum. Lawrence, MA: Small Planet Communications.

Rosenblatt, L. M. (2004). The transactional theory of reading and writing. In R.B. Ruddell \& N. J. Unrau (Eds.), Theoretical models and processes of reading (5th ed., pp.13631398). Newark, DE: International Reading Association.

Sarason, S. (1982). The culture of the school and the problem of change. Boston: Allyn \& Bacon.

Vygotsky, L. (1962). Thought and language. Cambridge, MA: MIT Press.

Wilhelm, J. D. (2009). The power of teacher inquiry: Developing a critical literacy for teachers. Voices from the Middle, 17(4) 